\title{
Hausärztliche RLV-Fallwerte im 3. Quartal 2010 weiter sehr uneinheitlich
}

— Mittlerweile liegt ein Vergleich der RLV-Fallwerte in den einzelnen Kassenärztlichen Vereinigungen nach Einführung der neuen Honorarverteilungsmechanismen vor. Seit dem 1.7.2010 wurden bekanntlich die sog. Vorwegleistungen und die mit einem deutlich höheren Budget ausgestatteten Qualitätszuschläge bei Hausärzten abgeschafft. An ihre Stelle sind nun durchweg Qualitätszuschläge (QZV) getreten, deren Volumen sich aus dem finanziellen Restbetrag nach Berechnung der Regelleistungsvolumen (RLV) ergibt.

Die Vergleichbarkeit der einzelnen Werte ist deshalb allerdings nicht mehr in gleicher Weise möglich, wie dies bis zum Ende des 2. Quartals 2010 der Fall war. Den regionalen KVen wurde nämlich bei der Gestaltung der OZV ein großer Gestaltungsspielraum zugebilligt. Dies hat dazu geführt, dass bestimmte Leistungen, für die der Bewertungsausschuss ein OZV festgelegt hat, in einer KV im RLV aufgegangen sind, in einer anderen KV als OZZV erhalten geblieben sind und bei einer weiteren KV als sog. „Freie Leistung“ und damit außerhalb RLV und OZV definiert wurden.

\section{MMW Kommentar}

Auslöser für den Paradigmenwechsel zum 1.7.2010 war die zunehmende Verteilungsproblematik im fachärztlichen Bereich. Da Vorwegleistungen über alle Fachgruppen hinweg vorab, aber zulasten der MGV vergütet wurden, blieb bei einigen Facharztgruppen nicht genügend Geld zur Aus- stattung der RLV übrig. Mit der Änderung sollten nunmehr die RLV gestärkt werden, was aber rein optisch im hausärztlichen Bereich nicht gelungen sein dürfte. Allem Anschein nach hätte man deshalb dort auf diese neue, sehr komplizierte Regelung verzichten können.

\section{Abbildung 1}

\section{RLV-Fallwerte im 3. Quartal 2010}

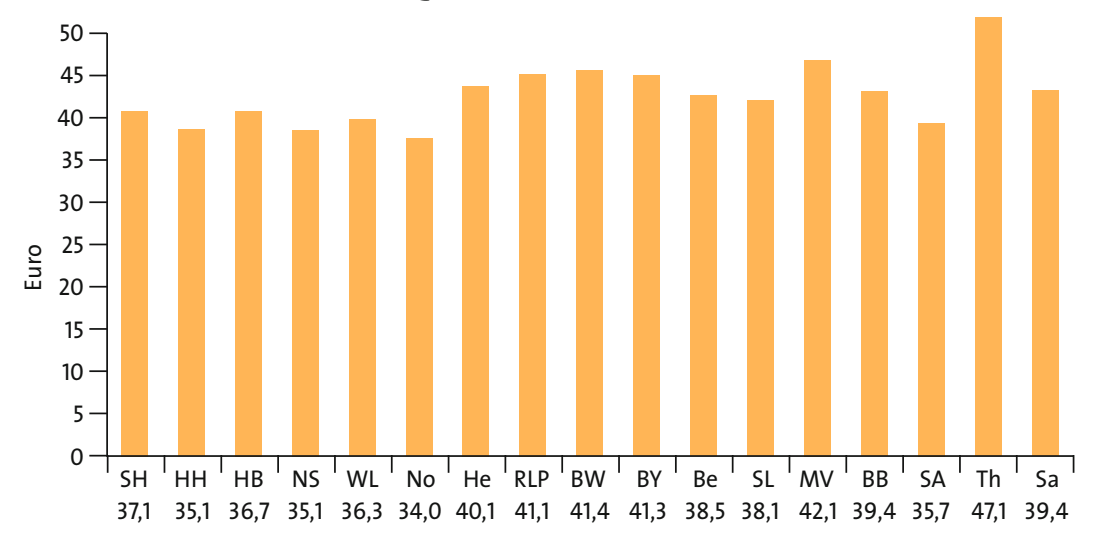

Die RLV-Fallwerte in Euro im 3. Quartal 2010 (Quelle: KBV) zeigen immer noch Unterschiede durch das regional ungleiche Finanzvolumen bei der morbiditätsbedingten Gesamtvergütung (MGV).

\section{Neue Haftungsregelungen für Gemeinschaftspraxen}

— Die meisten Berufsausübungsgemeinschaften (Gemeinschaftspraxen, MVZ) werden in der Rechtsform der Gesellschaft bürgerlichen Rechts (sog. BGB-Gesellschaft) geführt. Bei dieser Gesellschaftsform gibt es nur wenige zwingende rechtliche Vorgaben, was dazu führt, dass alle Praxispartner unbegrenzt mit dem Privatvermögen für alle gesellschaftsbezogenen Handlungen der anderen Gesellschafter haften.
Eine Problemlösung stellt die Rechtsform der Partnerschaftsgesellschaft (PartGG) dar. Hier besteht eine Haftungsbeschränkung. Allerdings wird bei der Partnerschaft nur das Privatvermögen geschützt, das Gesellschaftsvermögen haftet unbeschränkt.

\section{MMW Kommentar}

Der Bundesgerichtshof (BGH) hat diese Haftungsbeschränkung kürzlich weiter reduziert. Die Entscheidung wurde zwar für eine Partnerschaft von Rechtsanwälten getroffen (Az. IX ZR 12/og), ist jedoch auf Ärzte übertragbar. Die neue Regelung besagt, dass ein neu eintretender Partner in einer Partnerschaftsgesellschaft auch für Behandlungsfehler haftet, die vor seinem Eintritt von einem anderen Partner gemacht wurden, sofern der neue Partner die Behandlung des betreffenden $\mathrm{Pa}$ tienten übernimmt. 